\title{
UNDERSTANDING THE EMBEDDED CARBON CHALLENGES OF BUILDING SERVICE SYSTEMS
}

\author{
Hein, Maria (1); \\ Jones, Darren Anthony (2); \\ Eckert, Claudia Margot (2) \\ 1: KTH Royal Institute of Technology; \\ 2: The Open University
}

\begin{abstract}
Energy consumed in buildings is a main contributor to $\mathrm{CO} 2$ emissions, there is therefore a need to improve the energy performance of buildings, particularly commercial buildings whereby building service systems are often substantially over-designed due to the application of excess margins during the design process.

The cooling system of an NHS Hospital was studied and modelled in order to identify if the system was overdesigned, and to quantify the oversizing impact on the system operational and embodied carbon footprints. Looking at the operational energy use and environmental performance of the current system as well as an alternative optimised system through appropriate modelling and calculation, the case study results indicate significant environmental impacts are caused by the oversizing of cooling system.

The study also established that it is currently more difficult to obtain an estimate of the embodied carbon footprint of building service systems. It is therefore the responsibility of the machine builders to provide information and data relating to the embodied carbon of their products, which in the longer term, this is likely to become a standard industry requirement.
\end{abstract}

Keywords: Decision making, Case study, Requirements, Design Margins, Overdesign

\section{Contact:}

Jones, Darren

The Open University

STEM-EI

United Kingdom

darren.a.jones@open.ac.uk 


\section{INTRODUCTION}

The global market for heating, cooling and ventilation system was $\$ 240.8$ billion in 2019 and is projected to reach about 367.5 billion U.S. dollars by 2030, based on a compound annual growth rate (CAGR) of 3.9 percent between 2020 and 2030 (statistica, 2020). Throughout the UK and Europe almost $20 \%$ of the electrical energy we use in manufacturing and commercial operation is consumed by the HVAC systems (HVDS, 2017). According to the International Energy Agency (IEA) building service systems such as air conditioners and electric fans to stay cool already accounts for about a fifth of the total electricity used in buildings around the world - or $10 \%$ of all global electricity consumption (IEA, 2018). Energy usage in buildings is a major contributor to Carbon Dioxide $\left(\mathrm{CO}_{2}\right)$ emissions. Renovation of the existing building stock can potentially decrease the total energy consumption by $5-6 \%$ and reduce $\mathrm{CO}_{2}$ emissions by approximately $5 \%$ (European Commission, 2019). To reach carbon-neutrality by 2050 , the EU needs to improve the energy efficiency in buildings (BPIE, 2020), particularly commercial buildings that are often substantially overdesigned. Overdesign of building service systems, when using traditional static-load and rule-of-thumb approaches, can result in a $50 \%$ oversizing and is estimated to cost $£ 224 \mathrm{bn}$ globally according to the Chartered Institution of Building Services Engineers (Butler, 2020). Margins, i.e. percentage increases of the requirements to provide a buffer, often caused by insufficient communication amidst stakeholders, in the design process of building service systems result in an oversizing of these systems (Jones and Eckert, 2019). This has significant environmental impacts both in terms of the operational and embodied carbon footprints. An aim of this paper is to show the carbon footprint caused by excess design margins that lack quantifiable justification, and to demonstrate a more environmentally optimal alternative. Building on a case study of a replacement cooling system within an NHS Hospital, it illustrates the excess operational carbon footprint (OCF) of the system and discusses the challenges of obtaining information relating to the embodied carbon footprint (ECF).

Section 2 sets the context from the literature review related to the environmental impacts of oversizing. A description of the research methodology is provided in section three. Section four presents a case study of an overdesigned cooling system at an state-funded National Health Service (NHS) Hospital where the current system's carbon footprint is compared to a more environmentally optimal alternative. Challenges with embodied carbon and the importance of optimised design processes are discussed and reflected upon in section five and conclusions are drawn in section six.

\section{LITERATURE REVIEW}

Overdesign is often a response to risk. The management of margins, as a means to handle risk, needs to be seen in the wider context of resilience on two related levels. Firstly, the ability of the system to function within specified parameters; therefore, resilience is provided by maintaining specific operating conditions. Where the system is impacted by some form of previously envisaged disturbance, the system's resilience is measured by its speed and ability to return to its original state; such systems may fail catastrophically under unforeseen circumstances. Secondly, the resilience of the overall system to maintain its core functions, for example for a hospital to provide adequate medical care. Resilient systems may include multiple approaches to service provision, such as redundancy or spare capacity and the use of experienced, trained management, empowered to act competently in an emergency (Meerow et al, 2016).

\subsection{Oversizing}

A margin is "the extent to which a parameter value exceeds what it needs to meet its functional requirements regardless of the motivation for which the margin was included" (Eckert et al., 2013). Eckert and Isaksson (2017) distinguish between safety margins, which are added to the requirements often in accordance with regulations and design margins, which are designed into a system at the early stages to protect it from adverse effects of the change in a later stage. When analysing the margins on an existing system, there are two elements to the margins: a buffer against uncertainties and an excess which clearly exceeds the requirements. Products can have significant overdesign as both safety margins and design margins are often added in the design process, independently of the other which results in excessive margins (Eckert and Isaksson, 2017). One of the main reasons for overdesign is the lack of clear guidelines and poor communication (Soliman, 2012). The practice of "rule-of-thumb" decisions in design processes commonly result in oversizing. Adding margins in the design process can 
reduce design costs, however, the savings are counteracted by the increased initial capital cost, since overdesigned equipment is more expensive (Abhang, 2020). An example of an oversized boiler system at an NHS Hospital, where the average heating demand over a year is only $3.5 \mathrm{MW}$, yet the upgraded boiler system resulted in a total heating capacity of $26 \mathrm{MW}$ (Jones and Eckert, 2017), shows that the annual standing losses were nearly 5,400 MWh. This indicates financial losses of over £156k per annum, given the gas unit cost year 2014/15. Over the boilers' 20 years lifetime, this generates a total loss of over $£ 3 \mathrm{M}$ and a Carbon Dioxide emissions equivalent (abbreviated $\mathrm{CO}_{2}$-eq) of 992 tonnes (Jones et al., 2018); $\mathrm{CO}_{2}$-eq is a metric measure used to compare the emissions from various greenhouse gases on the basis of their global-warming potential (GWP), by converting amounts of other gases to the equivalent amount of carbon dioxide with the same global warming potential.

Building service systems are designed to continue to operate in the event of system failure, this sustained resilience is achieved through the implementation of redundancy design principles (International Atomic Energy Agency, 1986). Redundancy factors ensure reliability in the event of a full and partial system failure (Chen and Crilly, 2014). Having more chiller units than is necessary to meet the building maximum demand is an example of system redundancy. The degree of redundancy applied is dependent upon a building's risk and resilience requirements, in the case of hospitals, these typically work on the basis of an N+1 redundancy strategy, i.e., the redundancy of a single chiller $(\mathrm{N})$ is match by a further 'back-up' chiller (+1) to provide the required resilience (Jones and Eckert, 2017). Typically, redundancy scenarios utilise building service systems on a like-for-like basis.

\subsection{Embodied versus operational carbon}

The environmental impact of a building is made up of two factors, embodied and operational emissions, which can be quantified in an LCA (Vilches et al., 2017). Previously the focus has been primarily on reducing the operational emissions as they have been believed to cause the greatest environmental impacts (Lockie and Berebecki, 2012). The carbon intensity is a measure of how much $\mathrm{CO}_{2}$-eq emissions are produced per kilowatt hour of electricity consumed, expressed as the grid carbon factor. The value fluctuates all the time, depending on the type of generated electricity and the demand for power, therefore it also changes over the course of a day (Carbon Intensity, 2020).

Whilst there are multiple energy policy frameworks that aim for 'so-called' zero carbon homes, few emission policy frameworks relate to the materials and construction procedures of buildings (IbnMohammed et al., 2013), which includes the collection and processing of raw materials, transportation, construction, maintenance and demolition, among others. However, studies show that there is a growing interest on the embodied emissions (Biswas, 2014). Lockie and Berebecki (2012) state that this is likely due to the fact that the embodied carbon emissions of buildings increase in proportion as a result of the reduced operational emissions (Lockie and Berebecki, 2012). Recent LCA studies show that the proportion embodied emissions is converting from $20 \%$ to $40 \%$ versus the energy of the operational phase (Vilches et al., 2017). The growing attention of embodied emissions is believed to result in requirements on organisations in the construction sector to declare information on the embodied emissions of their buildings. The challenge with this, is the enormous amounts of data required for the quantification of the embodied emissions, which can both be difficult to collect and time consuming as it is a more complex procedure than to monitor the operational use (Yeo et al., 2016). There are energy efficiency programs that incentivise users to reduce the initial cost of installing energy efficient systems. One example regarding building services' incentives demonstrates that financial aid only applies for units whose capacity will be completely utilised, and that oversized systems will not obtain supplementary incentives, and neither will redundancy units (Consumers Energy, 2020). Embodied emissions have previously primarily been overlooked but are receiving increased attention, according to Jordan and Bleischwitz (2020). Implementing incentives regarding the embodied carbon can contribute to the switch towards sustainable development as it can encourage the use of low carbon products. Green building rating schemes enables for increased focus on the materials' embodied emissions, as well as implements incentives for producers to be transparent about their product's or service's environmental impacts. An example of this is through environmental product declarations (EPDs), which can result in credits that can be used to obtain higher ratings in environmental evaluations. EPDs have become an entrenched tool in the European building industry for quantifying environmental impacts embodied in building material (Jordan and Bleischwitz, 2020), which may potentially include oversizing in the evaluation in the future. 


\subsection{Oversizing in cooling systems}

A report by Soliman (2019) argues that overdesign of pumps, heat exchangers, and compressors greatly raises the energy consumption and reduces the general plant performance (Soliman, 2019). This is partially caused by wrong design assumptions (Beggs, 2009). HVAC systems are rarely designed correctly, as they have to cope with extreme periods, such as extraordinary weather and heightened demand, resulting in disproportionate margins as they lack a quantified and reasonable rationale. Therefore, there is a need for a suitable sizing method that includes a reasonable security factor (Djunaedy et al., 2011). Older systems can be oversized as a safety measure and the demand on them goes down, as well as up. Worn-out components are often replaced with the bigger alternative, without a reasonable rationale (Swedish Energy Agency, 2015). Absorption chillers require the heat from boilers to function. The energy efficiency of which a boiler converts fuel into heat drops rapidly at a low load, which is defined as only $40 \%$ under its maximum capacity. As many boiler plants experience varying demands throughout the year, it is therefore a strategic decision to select multiple boiler sizes to match the fluctuating demand. For periods of low demand, a smaller boiler could operate at nearly full load, whereas one or two boilers of a larger size could cope with peak loads, such as the winter (Natural Resources Canada, 2016). Due to low heating loads a boiler might operate for only a short period of time, and then turn off and cool down. For example, if the demand is half of the boiler's minimum capacity, it will operate at a minimum for a short while and then turn off, with half of the generated heat going to waste. This type of operation is called short cycling, whereas dry cycling is when energy losses occur as a result of standing losses. According to the Swedish $\|$ Energy Agency (2013a), oversized cooling systems also result in reduced energy efficiency, and states that the energy losses can account for $10-20 \%$ of the energy consumption, and the same number applies to oversized heating systems.

Furthermore, building services that are overdesigned often result in elevated expenditure and energy usage of other installations. A chiller plant that is dimensioned too large for the purpose is an example of this, where the electrical system providing it with power also needs higher-capacity conductors, transformers and protection equipment (Abhang, 2020); this also results in oversized pumping systems (Trane, 2011). In addition, increased maintenance costs follow as oversized components tend to be switched on and off and wear out requiring more reparation and replacement than an optimised plant (Abhang, 2020) The Swedish \|Energy Agency (2013a) presents that overdesigned cooling systems often run poorly and with a greater wear on the various components, such as pumps and valves, than a system that is sized to match the capacity with the demand.

\section{RESEARCH METHODOLOGY}

The issue of excess carbon footprint caused by overdesign within the context of this paper originated from wider research on strategic energy management in Hospital Trusts by the second author who has over 30 years' experience of working in energy management. The NHS developed a strategy in 2007 to reduce its carbon footprint, one of the first national health systems to do so (Bawden, 2019).

This paper reports and focusses on an extended case study looking specifically at the carbon footprint of a chilled water system upgrade. The initial case study investigated an NHS Hospital, that had replaced an old inefficient oversized chilled water system, with a new efficient, albeit oversized system in 2019 (Jones and Eckert, 2020). The Hospital had a considerable accumulation of maintenance problems and there was concern for a disastrous breakdown of the worn-out building service system infrastructure. A two-phase development project was realised due to energy performance contracting which enables a private sector 'funding mechanism' for hospitals to acquire considerable infrastructure system updates including large boiler and chiller systems. Phase 1 was performed over the years 2016/2017 and it included the installation of a combined heat and power (CHP) unit, a waste heat combination boiler, an absorption chiller, heating and chilled water (CHW) pump systems, as well as a $1.6 \mathrm{~km}$ underground link from the main hospital to a secondary hospital. Phase 2 was performed over the years 2017/2018 and consisted of the installation of one electric and one absorption chiller and seven heat rejection units, so-called adiabatic coolers, mounted on the roof (Jones and Eckert, 2020).

The original case study involved seven face to face interviews in 2019 with the incumbent Estate Manager and his predecessor, the Operational Manager, and leading representatives of the contractors 
(Jones and Eckert, 2020). In addition, project documents were analyses to elicit project timelines, design considerations and decision processes as well as the post installation performance evaluation.

The extended research reported in this paper used a mixed-methods approach that included: a thorough document analysis, site visit to case study hospital, modelling and calculations of case study building services and optimised system, as well as semi-structured discussions. A site visit to the NHS Hospital on 13th February 2020, which included a tour by and discussion with the Senior Operational Estates Manager, allowed for collection of information regarding the building service system design, the individual components, and the complex building's energy usage. From this data the authors developed models in Visual Paradigm of the various components of the building service system, their capacities, and system interconnections. For each major component of the building service system, the manufacturer was contacted in order to gather environmental impact data, specifically the embodied carbon data of their plant and equipment. Efforts to contact all known manufacturers, seven in total, were made through emails and phone calls, and four manufacturers replied. Data concerning the products' operational energy efficiencies and embodied carbon was requested. In addition, data regarding the energy usage was requested from the NHS Hospital. Based on the obtained information, it was possible to identify the potentially oversized components, which were the focus for the remaining part of the case study, and for which carbon footprint calculations were performed.

In order to calculate the components' carbon footprints, different types of calculation methods were explored, based on available data. An evaluation of an appropriate grid carbon factor was carried out through investigation, based on the scope of the grid, historically and a future prediction. This was necessary to calculate the operational carbon footprints of the current system and the optimised alternative, for the current scenario, as well as a possible future scenario. The embodied environmental impacts of a unit are divided up into multiple stages in an environmental product declaration, and the data represent the total environmental impacts over the unit's lifetime. The estimations of the embodied carbon footprints of the units in the system are based on available EPDs of units similar to the ones in the current system. There was one EPD for an average electric chiller (Daikin Applied, 2016) and one for a pump (Sulzer, 2013). The first stage is the product phase, the so-called initial ECF, which includes the raw material supply, transport and manufacturing. The second phase represents the recurring $\mathrm{ECF}$, that includes the use and maintenance emissions, which for a chiller represent the emissions from refrigerant leakage and refrigerant supply. The recurring phase in the EPDs used in this case study did not include data regarding repair and replacements, and this factor could therefore not be included in the estimations of the units' ECFs. The final stage, the end-of-life phase includes the disposal and recycling of the product (Daikin Applied, 2016). The final stage is excluded in the case study since it does not affect the production of the specific units themselves and instead reduces the initial ECF of the units which will use the recycled materials.

\section{OVERSIZING AND CARBON EMISSIONS IN THE CASE STUDY HOSPITAL}

In the tender and specification documents for the upgrade, the Hospital organisation requested that the chilled water refurbishment offered an $\mathrm{N}+1$ supply capacity of $2.5 \mathrm{MW}$. Based on measurements and calculations by the Energy Performance Contract (EPC) provider that was responsible for the design of the system, a summer (peak) cooling demand of $900 \mathrm{~kW}$ was considered appropriate. A margin of $20 \%$ was practiced to compensate for errors in the calculation methodology, resulting in a peak demand of $1,080 \mathrm{~kW}$; just over $1 \mathrm{MW}$. Therefore, the Phase 1 absorption chiller (\#2), designed with a capacity of 1.157 MW was adequate to fulfil the expected peak demand requirements. However, Phase 2 (chillers \#1 and \#3) was realised to allow for the $\mathrm{N}+1$ configuration in respect to both heat and electric cooling, providing system redundancy under various system fault scenarios (Jones and Eckert, 2020).

\subsection{Cooling system oversizing}

Figure 1 below provides a conceptual model of the cooling system that consists of a 1.6 MW Electric chiller, a 1.157 MW Low Temperature Hot Water (LTHW) Absorption chiller and a 1.0 MW High Temperature Hot Water (HTHW) Absorption chiller (labelled 1, 2 and 3), resulting in a total cooling capacity of $3.76 \mathrm{MW}$. The function of the chillers is to generate cold (chilled) water that absorbs unwanted heat from the hospital and returns this back to the chiller heat exchanger (located inside each chiller) via return water chiller distribution pumps (see right of figure). In addition to the chiller plant, Figure 1 shows the inclusion of seven adiabatic heat rejection units (coolers) which are located on the 
Hospital roof, each with a heat rejection capacity of 1.05 MW resulting in a total heat rejection capability of 7.35 MW; the function of the adiabatic heat rejection coolers is to remove heat from the chilled water system and expel this to atmosphere via inbuilt heat transfer radiators. When comparing the size of the installed plant with a site demand of just over $1 \mathrm{MW}$, it is clear that the chiller system is over dimensioned. The various chilled water and heat rejection distribution pumps are also illustrated.

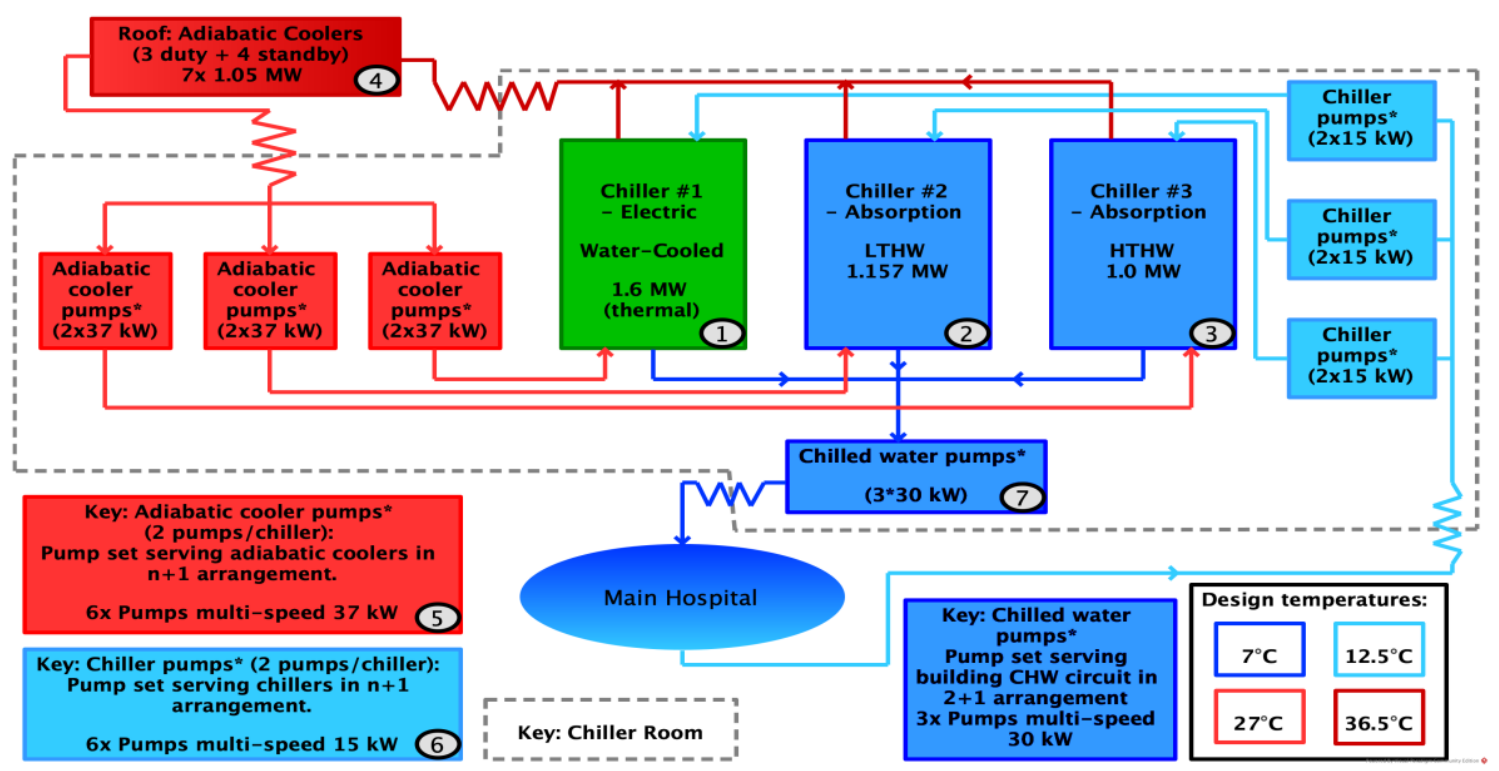

Figure 1. Conceptual model of cooling system upgrade

Through analysis of site-specific data, it was possible to determine an average cooling demand in the winter of just under $200 \mathrm{~kW}$ and the average summer cooling demand just short of $1 \mathrm{MW}$, with a peak requirement just short of 1.1 MW in August. Whereas the average cooling demands in the spring and autumn both lie near $500 \mathrm{~kW}$, similar to the yearly average of approximately $550 \mathrm{~kW}$. The overcapacities of the chillers and adiabatic coolers versus the cooling demands are illustrated in Figure 2. Figure 2 also compares the current system overcapacities with an improved alternative system design that has been optimised to an upper maximum capacity limit of $1.2 \mathrm{MW}$ further allowing an additional $\mathrm{N}+1$ redundancy $(600 \mathrm{~kW})$, which is discussed in detail within section 4.2.

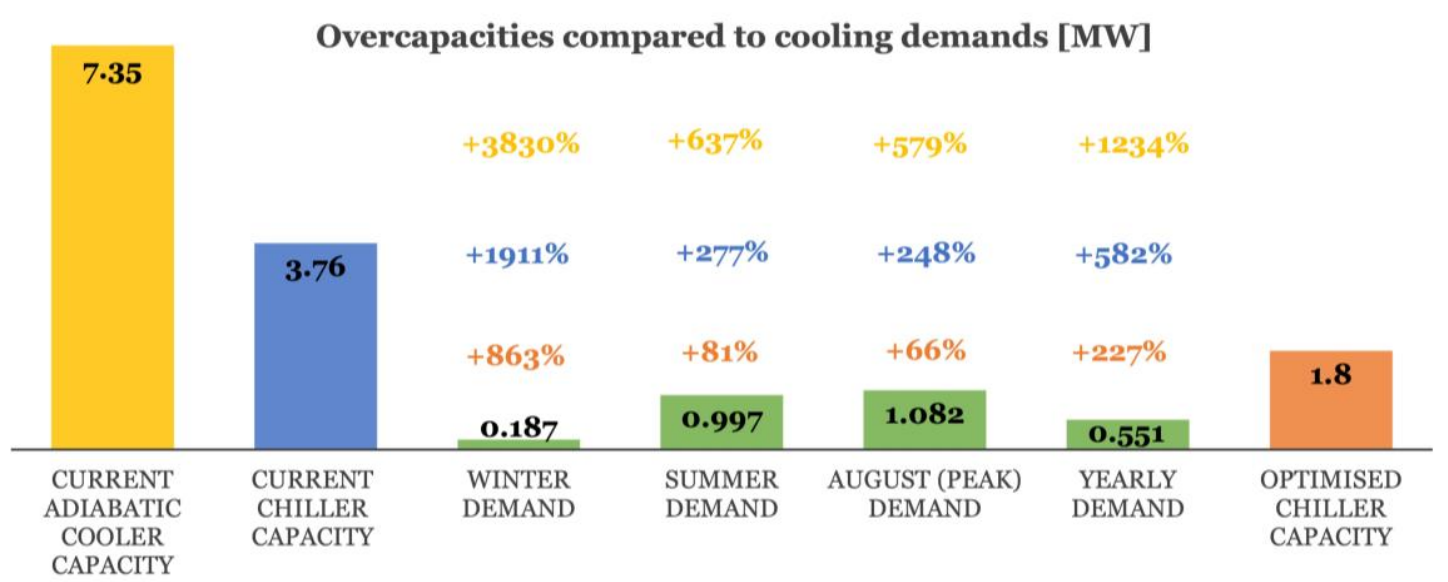

Figure 2. Current and improved system overcapacities versus actual cooling demands.

The cooling capacity of the chillers (labelled blue) represents an oversizing issue of $277 \%$ above the monitored summer demand and a heat rejection (labelled yellow) oversizing of 637\%. The oversizing compared to the yearly average cooling demand is nearly 6 times for the chillers and over 12 times for the adiabatic coolers. For clarity, the terms 'overcapacity' and 'oversizing' refer to a combination of two elements; buffer, which enables a response to uncertainty providing resilience and safety, and excess, which is the additional capacity that clearly exceeds the requirements. Hence, whilst buffer is a functional necessity, excess can be considered as waste, leading to poor performance and inefficiency. It is therefore important to note that whilst a proportion of buffer is required within the overall sizing 
strategy, excess in systems that are hundreds of percent over the 'normal' day-to-day requirements, should be avoided. A simpler and potentially improved system was investigated, modelled and presented in the next section.

\subsection{Sizing of improved alternative system}

The alternative system was based on the idea to electrify the NHS Hospital rather than having a reliance on heat generation from boilers and the CHP to provide cooling effect via the abortion chillers. Whilst a system cannot be optimised unless the specific requirements are known, the improved alternative system does reflect upon the site maximum cooling demand and hence provides an optimised system against this upper capacity limit. The alternative setup consisted of air-cooled electric chillers placed on the roof, negating the need for separate heat rejection units since the heat rejection capability is integrated into the chillers themselves. This arrangement also removes the need for cooler pumps resulting in less pipework and associated infrastructure, eliminating both the OCF and ECF of the currently installed adiabatic cooler pumps. Two $600 \mathrm{~kW}$ air-cooled electric chillers were chosen to provide sufficient capacity to cover the peak demand of $1.1 \mathrm{MW}$; a further $600 \mathrm{~kW}$ chiller was modelled to provide the $\mathrm{N}+1$ redundancy, should one chiller fail; $\mathrm{N}+1$ redundancy is a form of resilience that ensures system integrity in the event of component failure or during maintenance downtime (the redundancy of a single chiller $[\mathrm{N}]$ is substituted by a chiller of matched capacity [+1]). Based on this arrangement, a single chiller would cover the yearly average demand of $0.551 \mathrm{MW}$. As illustrated in figure 2, whilst the capacity of the alternative chiller design still provides capacities larger than the requirements; hence an oversizing issue of $81 \%$ during summer months (labelled orange), this system is far less oversized than the currently installed system, whilst meeting the various seasonal demands effectively. The reduced chiller capacity also reduces the size and number of the chiller pumps required, whereby two primary pumps are evaluated to suffice. A conceptual model of the optimised system is shown in Figure 3, whereby chilled water is pumped 'to and from' the Hospital via a plate heat exchanger.

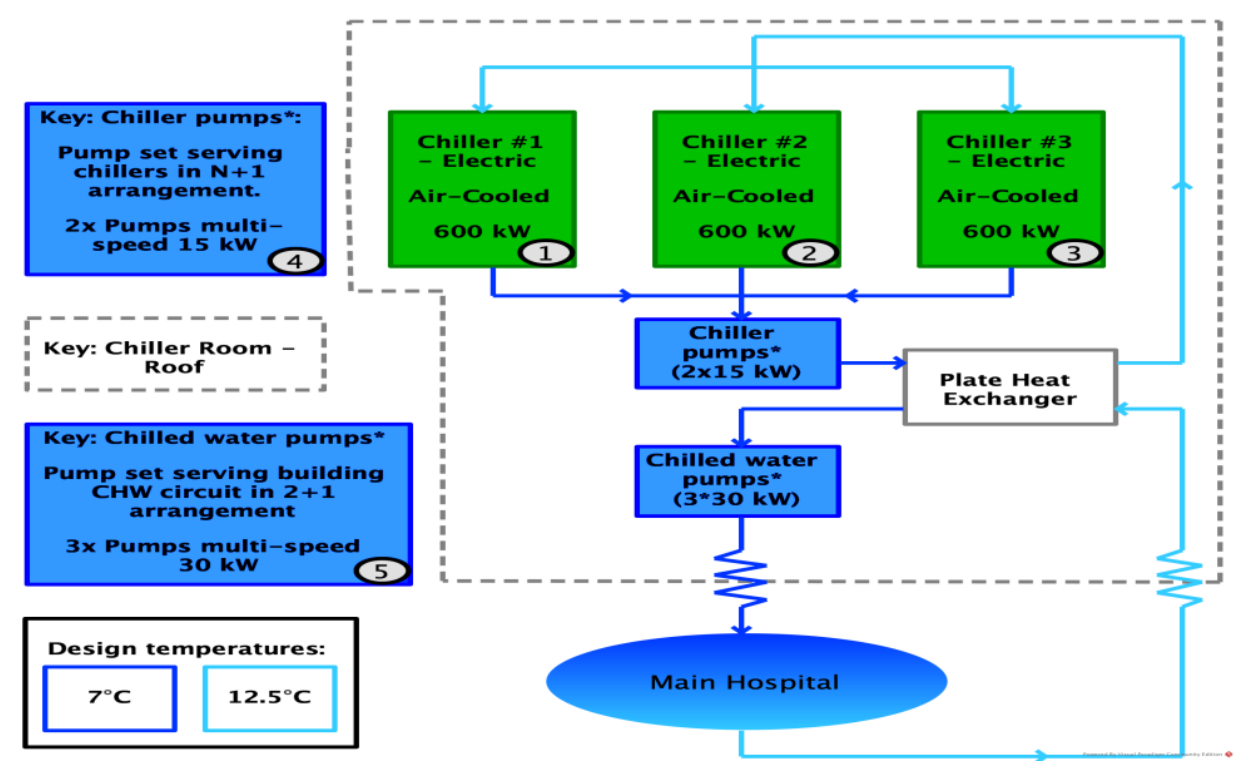

Figure 3. Conceptual model of improved cooling system

\subsection{Carbon footprints of the installed and improved systems}

From site energy consumption data and engineering calculations it was determined that the current installed cooling system has an estimated OCF of 887 tonnes $\mathrm{CO}_{2}$-eq p.a., this excludes the adiabatic coolers. Whereas the optimised alternative has an estimated OCF of 372 tonnes $\mathrm{CO}_{2}$-eq p.a. This results in a yearly OCF difference of approximately $515 \mathrm{CO}_{2}$-eq. The estimated ECF of the current system was 30 tonnes $\mathrm{CO}_{2}$-eq p.a., whereas the optimised system had an ECF of just 5.7 tonnes $\mathrm{CO}_{2}$ eq p.a., a difference of more than 24 tonnes $\mathrm{CO}_{2}$-eq p.a. The optimised system would also result in a less complex and reduced pipework system, as illustrated in Figure 3, which would likely lower the ECF further. The carbon footprints of the various system components are presented in Figure 4. The current cooling system has a calculated carbon footprint of 917 tonnes $\mathrm{CO}_{2}$-eq, out of which the ECF 
represents $3.3 \%$. Whereas the optimised cooling system has an estimated carbon footprint of 378 , out of which the ECF represents $1.5 \%$. The optimised system could therefore result in a yearly reduction of approximately 539 tonnes $\mathrm{CO}_{2}$-eq when compared to the current system; an estimated annual carbon footprint saving of 59\%. Whilst system carbon footprints are based on 2019 carbon factors, the optimised system OCF being electrically driven, will improve further over time, due to the decarbonisation of the power grid.

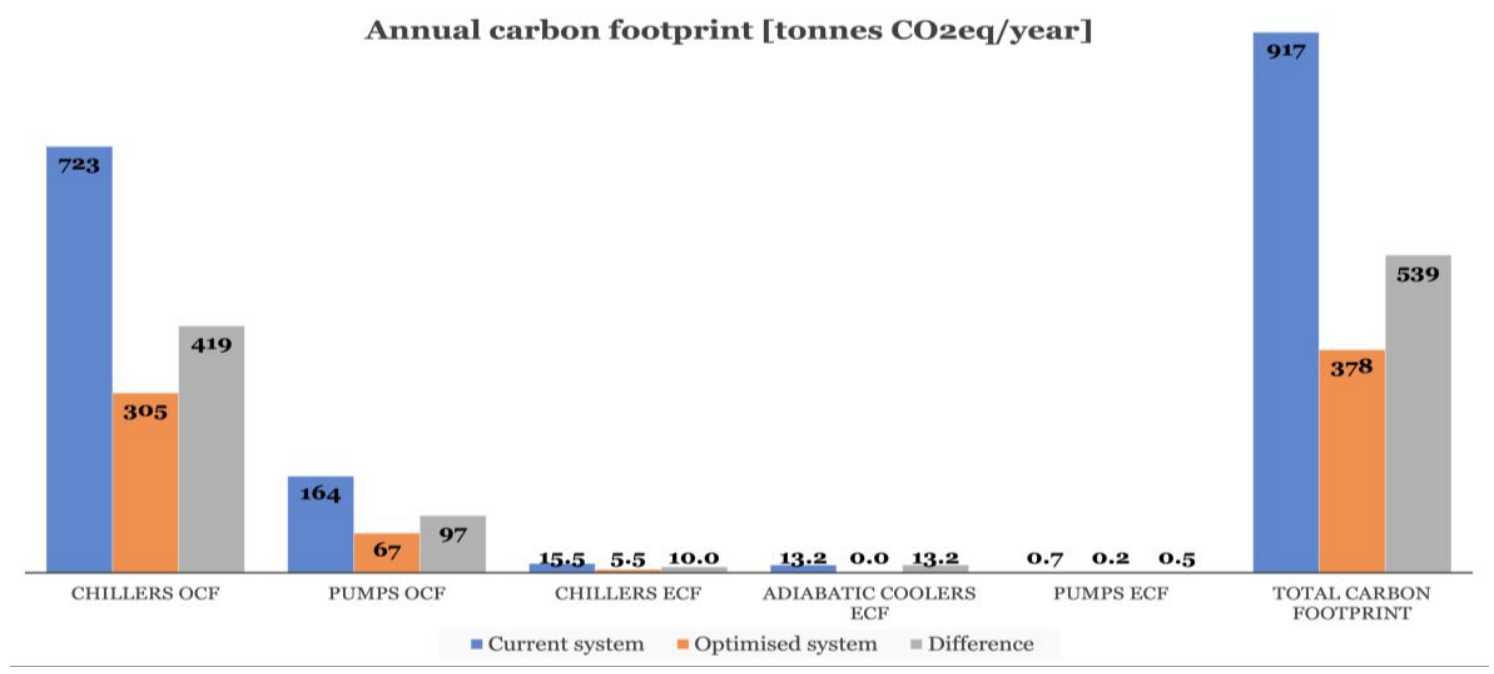

Figure 4. OCFs and ECFs p.a. of current and improved system components

\section{DISCUSSION - UNDERSTANDING THE EMBODIED CHALLENGES}

The operational carbon can be calculated from the building's energy data. For Hospital's the challenges lie in understanding the nature of the demand, which at present cannot be broken down clearly to classes of use, this makes it difficult to predict the long-term trajectory of energy use. This information could be obtained through suitable sensors and improved data. A greater challenge may lie in establishing the embodied carbon. None of the manufacturers had information about their product's ECF. The manufacturer's customer service of the combi steam boiler replied to the requested ECF in an email (2020, March 13th): "Embodied carbon footprint would be the equivalent $\mathrm{CO}_{2}$ produced for the manufacture of the boiler. I am not sure where we would be able to obtain this value".

The customer service of the adiabatic cooler pumps (Figure 1 - label 5) and the chiller pumps (Figure 1 - label 6) manufacturer replied to the requested ECF in an email (2020, March 6th) accordingly: "Hmmm.. don't think we have been asked that one before! Am aware for the concept, and by breakdown of component materials by weight it out to be possible to calculate, but regret no one has put pen to paper on this so far". However, they did provide a list of the materials in their products, but regrettably, were unable to present a breakdown by weight, only that the materials were listed from the largest by weight to the smallest. The list follows: Cast iron (frame), electric steel (laminations), copper (windings), carbon steel (shaft) and high-grade aluminium (cast rotor).

These two replies indicate that the quantification of the ECF of building service system components is a missing piece of information. This is clearly demonstrated in the reply from the Company who stated that they might not have ever been asked that previously, and that it is possible by breaking down the separate components, calculating the carbon footprint individually and summing up the final quantity. Since there was no data of the ECF for any of the components in the system, it was not possible to calculate the specific equipment's embodied environmental impacts. However, the ECFs of the potentially oversized units were calculated through comparison with similar products.

While it is intuitive that an embodied carbon would be higher for a bigger machine, it is difficult to obtain and calculate the exact values. Embodied carbon is calculated in international trade on the level of entire countries based on a material flow analysis. In an analysis of the built environment the impact of building services is dwarfed by the impact of the building materials, notably concrete, which take up $10 \%$ of the world's energy consumption. It is estimated that in a conventional building the embodied energy could account for 2-38\% of the total life cycle energy and for a low energy building, this could range from 9-46\% (Sartori and Hestnes, 2007). Dixit et al. (2013) point out that one of the 
challenges of calculating the embodied carbon in buildings is the system boundaries included in the calculation; e.g., which life cycles phases or elements of the buildings are included. While they acknowledge that much of the carbon footprint of buildings comes from its use, they do not mention the embodied carbon of the building services. Companies can also analyse their own flows on the level of the entire production run, however, these companies also run into the system boundary issues for the machinery, as many of the processes are shared between different products.

Even if figures are difficult to obtain for building service equipment. It is an important consideration for the design of these potentially oversized systems. An oversized system clearly has more embodied carbon than an appropriately sized one. A modular system that only run some of the modules, still incurs the carbon of the redundant system. This points to upgradable systems as the best design solutions, where additional units can be acquired and installed as new demands become apparent.

In the case study hospital, it would theoretically be possible to review the performance of the chillers regularly to upgrade the systems over the winter, if more capacity is required. However, in the context of the NHS this is difficult, because of the way capital expenditure budgeting works.

\section{CONCLUSION}

The oversizing of the building service systems is a significant factor in the carbon footprint of buildings. Whilst the study was carried out pre-covid, even accounting for possible increased cooling requirements due to the layering of personal protective equipment (PPE), the case study chillers are still likely to be significantly oversized by factors of hundreds of percent. Whilst it is possible to calculate the operational carbon footprint of a system providing suitable sensors and data are in place, it is currently more difficult to obtain an estimate of the embodied carbon footprint of these systems. Commercial buildings often have redundant systems in place to safeguard against system failure, however, because these systems are seldom used, the total carbon footprint of this plant and equipment tends to arise from manufacturing and materials embodied carbon factors only. It is therefore the responsibility of the machine builders to provide information and data relating to the embodied carbon of their products, in order that perspective buyers can make informed environmental choices about the equipment they specify and purchase; in the longer term, this is likely to become standard information

requested by customers. At the same time the onus lies on the designers of specific building service systems to design systems that are appropriate for the given requirements, and assess the embodied and operational carbon of different design alternatives.

\section{REFERENCES}

Abhang, S., 2020. Over-Engineering: What are the Negative Effects? [online]. Nearby Engineers. Available: https://www.ny-engineers.com/blog/negative-effects-of-over-engineering [Accessed 2020-5-2].

Bawden, A., 2019. The NHS produces $5.4 \%$ of the UK's greenhouse gases. How can hospitals cut their emissions? The Guardian, 2019-9-18.

Beggs, C., 2009. Chapter 13 - Energy Efficient Air Conditioning and Mechanical Ventilation. Energy: Management, Supply and Conservation (Second Edition). C. Beggs, ed., p. 252-287.

Biswas, W.K., 2014. Carbon footprint and embodied energy consumption assessment of building construction works in Western Australia. Int Journal of Sustainable Built Environment, Vol. 3, No. 2, p.179-186.

Butler, S., 2020. Sizing the opportunity (Dynamic Modelling - Right-sizing HVAC) [online]. CIBSE - Chartered Institution of Building Services Engineers. Available: http://portfolio.cpl.co.uk/CIBSE/202003/52/ [Accessed 2020-3-5].

Chen, C. \& Crilly, N. (2014). Modularity, Redundancy and Degeneracy: Cross-Domain Perspectives on Key Design Principles. 8th Annual IEEE Systems Conference (SysCon), Ottawa, Canada, IEEE, pp. 546-553. https://doi.org/10.1109/syscon.2014.6819309

Consumers Energy, 2020. Incentives Catalog: Business Energy Efficiency Programs.

Daikin Applied, 2016. Environmental Product Declaration: Centrifugal Chillers [online]. Available: https://oslo.daikinapplied.com/api/sharepoint/GetDocument/Doc100/101.1_Daikin_EPD_Magnitude_centri fugal_chiller_v5.pdf [Accessed 2020-5-7].

Dixit, M.K., Culp, C.H. and Fernández- Solís, J.L., 2013a. System boundary for embodied energy in buildings: A conceptual model for definition. Renewable and Sustainable Energy Reviews, Vol. 21, p. 153-164.

Djunaedy, E., van den Wymelenberg, K., Acker, B., and Thimmana, H., 2011. Oversizing of HVAC system: Signatures and penalties. Energy and Buildings, Vol. 43, No. 2-3, p. 468-475.

Eckert, C., Earl, C., Lebjioui, S., and Isaksson, O., 2013. Components Margins through the Product Lifecycle. Product Lifecycle Management for Society. A. Bernard, L. Rivest, and D. Dutta, eds., Vol. 409, p. 39-47. 
Eckert, C. and Isaksson, O., 2017. Safety Margins and Design Margins: A Differentiation between Interconnected Concepts. Procedia CIRP, Vol. 60, p. 267-272.

European Commission, 2019. Energy performance of buildings directive [online]. Energy - European Commission. Available: https://ec.europa.eu/energy/en/topics/energy-efficiency/energy-performance-ofbuildings/energy-performance-buildings-directive [Accessed 2020-3-7].

HVDS, 2017. News Article - Recognise World Environment Day 2017 [online]. Available: https://www.hvds.co.uk/reduce-hvac-carbon-footprint/ [Accessed 2020-11-27]

Ibn-Mohammed, T., Greenough, R., Taylor, S., Ozawa-Meida, L., and Acquaye, A., 2013. Operational vs. embodied emissions in buildings-A review of current trends. Energy and Buildings, Vol. 66, p. 232-245.

International Atomic Energy Agency (1986), General design safety principles for nuclear power plants: a safety guide. Vienna: International Atomic Energy Agency.

International Energy Agency 2018. News Article - Air conditioning use emerges as one of the key drivers of global electricity-demand growth [online]. Available: https:/www.iea.org/news/air-conditioning-useemerges-as-one-of-the-key-drivers-of-global-electricity-demand-growth [Accessed 2020-11-27]

Jones, D.A. and Eckert, C.M., 2017. Overdesign in building services: the hidden energy use. Presented at 21st International Conference on Engineering Design (ICED17), Vancouver, Canada, 21.-25.08.2017.

Jones, D.A. and Eckert, C.M., 2019. Empowering Decision Makers to Avoid the Oversizing of Building Service Systems. Presented at Proceedings of the 22nd International Conference on Engineering Design (ICED19), Delft, The Netherlands, 5-8 August 2019.

Jones, D.A. and Eckert, C.M., 2020. Managing Margins: Overdesign in Hospital Building Services. Presented at International Design Conference - Design 2020.

Jones, D.A., Eckert, C.M., and Gericke, K., 2018. Margins leading to over-capacity. Presented at 15 th International Design Conference, p. 781-792.

Jordan, N.D. and Bleischwitz, R., 2020. Legitimating the governance of embodied emissions as a building block for sustainable energy transitions. Global Transitions, Vol. 2, p. 37-46.

Li, Q., Wen, B., Wang, G., Cheng, J., Zhong, W., Dai, T., ... \& Han, Z. (2018). Study on calculation of carbon emission factors and embodied carbon emissions of iron-containing commodities in international trade of China. Journal of Cleaner Production, 191, 119-126.

Lockie, S. and Berebecki, P., 2012. Methodology to calculate embodied carbon of materials. 1st edition. Coventry, UK: RICS.

Manish K. Dixit, Charles H. Culp, Jose L. Fernández-Solís, System boundary for embodied energy in buildings: A conceptual model for definition, Renewable and Sustainable Energy Reviews, Volume 21, 2013b

Meerow, S., Newell, J. P., \& Stults, M. (2016). Defining urban resilience: A review. Landscape and urban planning, 147, 38-49.

Natural Resources Canada, 2016. Increasing the energy efficiency of boiler and heater installations [online]. Available: https://www.nrcan.gc.ca/energy/publications/efficiency/industrial/cipec/6699 [Accessed 2020-5-11].

Sartori, I. and Hestnes, A.G., 2007. Energy use in the life cycle of conventional and low - energy buildings: a review article. Energy and Building, 39 (3), p. 249-257.

Soliman, M.A., 2012. Pitfalls of oversizing plant rotating equipment. Presented at Abu Dhabi International Petroleum Conference and Exhibition, Society of Petroleum Engineers.

Soliman, M.A., 2019. Adverse Effect of Oversizing Upstream Gas Oil Separation Plants on Energy Consumption. Presented at International Petroleum Technology Conference, International Petroleum Technology Conference.

Statistics (2020) https://www.statista.com/statistics/414960/global-market-for-commercial-and-residential-hvacsystems/

Sulzer, 2013. Environmental Product Declaration: Environmental and economic life cycle performance including climate-related data - SMD Double Suction Pump. Available: https://www.sulzer.com/-/media/files/aboutus/our-company/sustainability/epd/sulzer_epd_smd_pump.ashx?la=en [Accessed 2020-5-7].

Swedish Energy Agency, 2013a. Energy efficiency of large cooling systems).

Swedish Energy Agency, 2013b. Energy efficiency of large heating systems).

Swedish Energy Agency, 2015. Dimension your heating system correctly) [online]. Available: http://www.energimyndigheten.se/energieffektivisering/jag-vill-energieffektivisera-hemma/inkop-avprodukter/uppvarmning/varme--och-luftkonditioneringssystem/effektivisera-ditt-varmesystem/ar-dittvarmesystem-ratt-dimensionerat/ [Accessed 2020-5-3].

Trane, 2011. Chiller System Design and Control.

Vilches, A., Garcia-Martinez, A., and Sanchez-Montañes, B., 2017. Life cycle assessment (LCA) of building refurbishment: A literature review. Energy and Buildings, Vol. 135, p. 286-301.

Visual Paradigm, 2020. Ideal Modeling \& Diagramming Tool for Agile Team Collaboration [online]. Available: https://www.visual-paradigm.com/ [Accessed 2020-5-8].

Yeo, Z., Ng, R., and Song, B., 2016. Technique for quantification of embodied carbon footprint of construction projects using probabilistic emission factor estimators. Journal of Cleaner Production, Vol. 119, p.135-151. 